\title{
Systematic review comparing LABA, olodaterol, and indacaterol: limitations
}

This article was published in the following Dove Press journal:

International Journal of COPD

5 December 2014

Number of times this article has been viewed

\section{James F Donohue}

Pulmonary Diseases and Critical Care Medicine, UNC School of Medicine, Chapel Hill, NC, USA
Correspondence: James F Donohue Pulmonary Diseases and Critical Care Medicine, UNC School of Medicine, CB\# 7020, I 30 Mason Farm Road, 4th Floor Bioinformatics Building, Chapel Hill, NC 27599, USA Email james_donohue@med.unc.edu

\section{Dear editor}

Roskell et al present a systematic review comparing the long-acting beta ${ }_{2}$ agonists (LABA), olodaterol, and indacaterol in the July edition of the International Journal of Chronic Obstructive Pulmonary Disease. ${ }^{1}$ The end-points compared for the two LABAs were: change from baseline in trough forced expiratory volume in 1 second $\left(\mathrm{FEV}_{1}\right)$ at week 12; quality of life analyzed by change from baseline in St George's Respiratory Quotient (SGRQ; total score and proportion of responders) at week 12; transition dyspnea index (TDI), analyzed by change from baseline at week 12; use of rescue medication, analyzed by change from baseline in average number of puffs per day; and proportion of patients experiencing at least one exacerbation, analyzed in trials with a treatment duration of 24 weeks or longer reporting data for this outcome. The authors conclude that olodaterol and indacaterol have similar efficacy in patients with COPD.

The findings of this systematic review were questionable for several reasons, which were mostly related to missing data, the difference in the concomitant medication allowed between the trials of olodaterol and indacaterol, and the differences in COPD severity in the patient populations of the trials of the two LABAs. It should also be noted that four of the eight olodaterol trials were of a 6-week duration only, ${ }^{2,3}$ while all indacaterol studies had a follow-up of at least 12 weeks.

Regarding data sources, this systematic review was limited to articles published from 1 January 1990 through to 5 August 2011. However, data from several indacaterol studies published in this period were not included in the analysis. The excluded data were: TDI data from the INSIST trial; ${ }^{4}$ rescue medication data from the INTRUST 1 and 2 trials ${ }^{5}$; data on $\mathrm{FEV}_{1}$, SGRQ (total score and responders data) and TDI from the QBA149B1302 study; ${ }^{6}$ and TDI data from study QBA149B2354. ${ }^{7}$ Furthermore, data from some of the indacaterol studies were taken from other network meta-analyses ${ }^{8,9}$ instead of directly from the primary publications of the trials, which would explain the differences between some of the results in individual trial publications and the supplementary material.

The authors state that olodaterol and indacaterol were compared under "similar trial conditions"; however the difference in the use of concomitant medication between the trials of the two LABAs makes this statement also questionable. Concomitant maintenance bronchodilator use was allowed in most of the olodaterol trials. In six out of eight trials, ${ }^{2,10,11}$ patients were allowed a long-acting muscarinic agent (LAMA; tiotropium). 
A short-acting muscarinic agent (SAMA; ipratropium) and/or a xanthine (theophylline) were also allowed in all olodaterol trials as well as the rescue medication with short-acting beta ${ }_{2}$ agonist (SABA). ${ }^{2,3,10,11}$ In ten out of the twelve indacaterol trials (INTRUST 1 and 2 excluded), patients were not allowed any concomitant bronchodilator except for the rescue medication with SABA. ${ }^{4-7,12-18}$ Inhaled corticosteroids (ICS) were allowed in the trials of indacaterol and olodaterol. This heterogeneity in trial design would have affected the results and conclusions of the meta-analysis.

While some subgroup analyses were carried out to account for concomitant LAMA medication, these were limited to two subgroup analyses: one subgroup analysis of change from baseline of trough $\mathrm{FEV}_{1}$ in patients who were "LAMA-free"; and another of patients who were allowed "LAMA add-on therapy". Moreover, data were missing from these analyses; the LAMA-free analysis only included studies 1222.39 and 1222.40 of olodaterol ${ }^{3}$ and did not include those patients who were LAMA-free in studies 1222.11, $1222.12,1222.13,1222.14,1222.24$, and $1222.25,2,10,11$ therefore excluding relevant sources of data. Furthermore, no other subgroup analyses taking concomitant medications into account were carried out for any other outcomes such as TDI, SGRQ scores or response, rescue medication, or exacerbations.

Data from the studies INTENSITY, ${ }^{14}$ INSIST, ${ }^{4}$ and B $1302^{6}$ trials were not included in the Forest plot tables analyzing change in baseline $\mathrm{FEV}_{1}$ (LAMA-free and LAMA add-on analyses), as well as for the TDI, SGRQ, and SGRQ responders analyses. No explanation was given for this omission.

The differences found in disease severity between the trial populations of olodaterol and indacaterol were also a concern. Patients with COPD disease severity ranging from moderate to very severe COPD (Global initiative for chronic Obstructive Lung Disease [GOLD] stages II-IV) ${ }^{19}$ were included in the olodaterol trials, whereas the indacaterol trials included patients with moderate-to-severe COPD (GOLD stages II/III) ${ }^{19}$ only. As the authors acknowledge in the Discussion section of their paper, the olodaterol trials were not stratified for disease severity and therefore, the differences in patient populations and possible lung function response by disease severity could not be addressed in the meta-analysis.

The Methods section in the Abstract states that the systematic review was carried out to evaluate the efficacy and safety of olodaterol and indacaterol; however, no safety data were presented.
To conclude, the extent of the missing data from these analyses, the variation in concomitant medication allowed within the trials of the two LABAs, as well as the difference in disease severity between the trial populations, make it difficult to draw any meaningful conclusions regarding the relative efficacy of olodaterol and indacaterol.

\section{Disclosure}

The author reports no conflicts of interest in this correspondence.

\section{References}

1. Roskell NS, Anzueto A, Hamilton A, Disse B, Becker K. Once-daily long-acting beta-agonists for chronic obstructive pulmonary disease: an indirect comparison of olodaterol and indacaterol. Int J Chron Obstruct Pulmon Dis. 2014;9:813-824.

2. Feldman GJ, Hamilton JA, Nivens MC, Korducki L, LaForce C. The 24-h FEV1 Time Profile of Olodaterol Once Daily via Respimat ${ }^{\mathbb{\circledR}}$ and Formoterol Twice Daily via Aerolizer ${ }^{\circledR}$ in Patients with GOLD 2-4 COPD: Results from Two 6-week Crossover Studies. Springer Plus. 2014;3:419.

3. Lange P, Hamilton A, Tetzlaff K, Ting N, Derom E. The 24-hour lung function time profile of olodaterol once daily versus placebo and tiotropium in patients with moderate to very severe chronic obstructive pulmonary disease. J Pulm Respir Med. 2014;4:196.

4. Korn $\mathrm{S}$, Kerwin E, Atis S, et al. Indacaterol once-daily provides superior efficacy to salmeterol twice-daily in COPD: a 12-week study. Respir Med. 2011;105(5):719-726.

5. Mahler DA, D'Urzo A, Bateman ED, et al. Concurrent use of indacaterol plus tiotropium in patients with COPD provides superior bronchodilation compared with tiotropium alone: a randomised, double-blind comparison. Thorax. 2012;67(9):781-788.

6. Kinoshita M, Lee SH, Hang LW, et al. Efficacy and safety of indacaterol 150 and $300 \mu \mathrm{g}$ in chronic obstructive pulmonary disease patients from six Asian areas including Japan: a 12-week, placebo-controlled study. Respirology. 2012;17(2):379-389.

7. Center for Drug Evaluation and Research summary review document for indacaterol; 2011. Study B2354. Available from http://www.accessdata. fda.gov/drugsatfda_docs/nda/2011/022383Orig1s000ClinPharmR.pdf. Accessed August 29, 2014.

8. Cope S, Capkun-Niggli G, Gale R, Jardim JR, Jansen JP. Comparative efficacy of indacaterol $150 \mu \mathrm{g}$ and $300 \mu \mathrm{g}$ versus fixed-dose combinations of formoterol + budesonide or salmeterol + fluticasone for the treatment of chronic obstructive pulmonary disease - a network meta-analysis. Int J Chron Obstruct Pulmon Dis. 2011;6:329-344.

9. Cope S, Zhang J, Williams J, Jansen JP. Efficacy of once-daily indacaterol $75 \mu \mathrm{g}$ relative to alternative bronchodilators in COPD: a study level and a patient level network meta-analysis. BMC Pulm Med. 2012;12:29.

10. Ferguson GT, Feldman GJ, Hofbauer P, et al. Efficacy and safety of olodaterol once daily delivered via Respimat(R) in patients with GOLD 2-4 COPD: results from two replicate 48-week studies. Int $J$ Chron Obstruct Pulmon Dis. 2014;9:629-645.

11. Koch A, Pizzichini E, Hamilton A, et al. Lung function efficacy and symptomatic benefit of olodaterol once daily delivered via Respimat $(\mathrm{R})$ versus placebo and formoterol twice daily in patients with GOLD 2-4 COPD: results from two replicate 48-week studies. Int J Chron Obstruct Pulmon Dis. 2014;9:697-714.

12. Center for Drug Evaluation and Research summary review document for indacaterol; 2011. Study B2355. Available from: http://www. accessdata.fda.gov/drugsatfda_docs/nda/2011/022383Orig1 s000TOC. cfm. Accessed September 2, 2014. 
13. Beier J, Chanez P, Martinot JB, et al. Safety, tolerability and efficacy of indacaterol, a novel once-daily beta(2)-agonist, in patients with COPD: a 28-day randomised, placebo controlled clinical trial. Pulm Pharmacol Ther. 2007;20(6):740-749.

14. Buhl R, Dunn LJ, Disdier C, et al. Blinded 12-week comparison of oncedaily indacaterol and tiotropium in COPD. Eur Respir J. 2011;38(4): 797-803.

15. Dahl R, Chung KF, Buhl R, et al. Efficacy of a new once-daily longacting inhaled beta2-agonist indacaterol versus twice-daily formoterol in COPD. Thorax. 2010;65(6):473-479.

16. Donohue JF, Fogarty C, Lotvall J, et al. Once-daily bronchodilators for chronic obstructive pulmonary disease: indacaterol versus tiotropium. Am J Respir Crit Care Med. 2010;182(2):155-162.
17. Feldman G, Siler T, Prasad N, et al. Efficacy and safety of indacaterol 150 microg once-daily in COPD: a double-blind, randomised, 12-week study. BMC Pulm Med. 2010;10:11.

18. Kornmann O, Dahl R, Centanni S, et al. Once-daily indacaterol versus twice-daily salmeterol for COPD: a placebo-controlled comparison. Eur Respir J. 2011;37(2):273-279.

19. Global Initiative for Chronic Obstructive Lung Disease. Global Strategy for the Diagnosis, Management and Prevention of COPD. 2010; http:// www.goldcopd.org/uploads/users/files/GOLDReport_April112011. pdf. Accessed dd, mm, yyyy. 


\section{Authors' reply}

\author{
Neil S Roskell' \\ Antonio Anzueto ${ }^{2}$ \\ Alan Hamilton ${ }^{3}$ \\ Bernd Disse ${ }^{4}$ \\ Karin Becker ${ }^{5}$
}

'Statistics, Bresmed Health Solutions Ltd, Sheffield, UK; ${ }^{2}$ School of Medicine, University of Texas Health Science Center, San Antonio, TX, USA; ${ }^{3}$ Medical Department, Boehringer Ingelheim (Canada) Ltd, Burlington, ON, Canada; ${ }^{4}$ Medical Department, Boehringer Ingelheim $\mathrm{GmbH}$, Ingelheim am Rhein, Germany; ${ }^{5} \mathrm{Global}$ Health Economics and Outcomes Research, Boehringer Ingelheim GmbH, Ingelheim am Rhein, Germany

\section{Correspondence: Neil S Roskell}

BresMed Health Solutions Ltd, North Church House,

84 Queen Street, Sheffield SI 2DW, UK

Tel +44 II43094372

Email nroskell@bresmed.co.uk

\section{Dear editor}

My coauthors and I read with interest the letter to your journal from Professor James F Donohue in relation to our published article "Once-daily long-acting beta-agonists for chronic obstructive pulmonary disease: an indirect comparison of olodaterol and indacaterol". We appreciate that Donohue focuses the discussion on the unavoidable limitations of an indirect comparison given the existing trials/evidence base.

The aim of our research was to explore the best way to make indirect comparisons between two new and important the long-acting beta ${ }_{2}$ agonists (LABA) treatments in the absence of both, head-to-head comparative data and an evidence base free from trial design heterogeneity. We tried to ensure that our paper fairly discussed and acknowledged the limitations of the evidence base, and of the subsequent indirect comparisons throughout. We concluded that similar efficacy was seen for each treatment for trough baseline in trough forced expiratory volume in 1 second $\left(\mathrm{FEV}_{1}\right)$ when similar, although we acknowledge that identical trial conditions were not observed. Further, we acknowledged that we were not able to evaluate other important end-points due to the heterogeneity of the evidence base and the lack of published data; and that only the head-to-head studies could confirm the comparable effectiveness of olodaterol and indacaterol. One of our key findings and conclusions was to recognize the importance of different trial designs with respect to concomitant chronic obstructive pulmonary disease (COPD) medications, and how they affect clinical outcomes.
With respect to the quoted data exclusions, transition dyspnea index (TDI) data from the INSIST trial were not included as the data was not presented by the treatment group (which was the required format for inclusion in our analysis). Rescue medication data from the INTRUST 1 and 2 trials were not included due to late availability of the data (publication post-searches) during the analysis stage. Data on $\mathrm{FEV}_{1}$, St George's Respiratory Quotient (SGRQ; total score and responders data), and TDI from the QBA149 B1302 study was not included as our review only retrieved the abstract from ATS 2011 rather than the full publication (which was published after our search date). Also, we did not identify the relevant TDI data from study QBA149 B2354 during our review (as we could not access it via the link provided by Donohue in his reference list). Some data were taken from other network meta-analyses instead of directly from the primary publications of the trials, as in these cases the data were presented in more detail (ie, by treatment) in the metaanalyses papers rather than in the individual trial publications. In conclusion, we used all the publicly available data at the date of finalization of the evidence base for analysis.

Specifically, Donohue points out the heterogeneity in the evidence base with respect to concomitant COPD medication, baseline COPD severity, and trial length. In six out of eight olodaterol trials, patients were allowed a long-acting muscarinic agent (LAMA), a short-acting muscarinic agent, and/or a xanthine plus rescue short-acting beta ${ }_{2}$ agonist (SABA), whereas in ten out of twelve indacaterol trials, patients were not allowed any concomitant bronchodilator except for the rescue SABA use. This heterogeneity in trial design would have affected the results and conclusions of the meta-analysis, especially the 'full network' meta-analysis. We certainly agree to this point.

The heterogeneity between the trials with respect to concomitant COPD medications (not just LAMAs) was acknowledged and there is little one could do to adjust or remove this effect from the indirect comparison. We were intentionally clear on this point; see Table 1 in our paper where we list the concomitant COPD medication use across the evidence base in addition to the patient severity at baseline. ${ }^{1}$ Although we agree there is a reasonable chance that the difference in concomitant COPD medication use may affect responses, it is not clear whether this will affect relative treatment effects within trials. However, if it does affect the relative treatment effects, additional long-acting bronchodilator co-medication, as allowed in the olodaterol trials, is likely to limit the room for improvement and limit the bronchodilator response. 
A comment was raised regarding the exclusion of six olodaterol trials (subgroups thereof) in the "LAMA-free" analyses. In fact, we did perform these analyses, which yielded very similar results to the presented LAMA-free analyses. We chose to present only one of these results for shortness and concision in the paper and chose the analysis of those trials which were most alike in terms of trial design and inclusion criteria. Analyses of end-points other than trough $\mathrm{FEV}_{1}$ were not performed for the LAMA-free analyses as the relevant data was either not collected or not available.

Donohue correctly points out that INSIST, ${ }^{2}$ INTENSITY, ${ }^{3}$ and $\mathrm{B} 1302^{4}$ were not included in the direct meta-analysis forest plots in the Supplementary data. This is because only the placebo controlled trials were included in the direct meta-analyses (INSIST ${ }^{2}$ and INTENSITY ${ }^{3}$ did not include placebo), and $\mathrm{B} 1302^{4}$ did not present any relevant data for inclusion in our analysis.

A comment was made about the lack of safety data in our analyses. We did present the results for COPD exacerbations as one safety end-point, but we agree that it would be worthwhile to further explore safety outcomes in future meta-analyses.

With respect to the comment regarding use of 6- or 12-week change from baseline data in our analyses, we believe that a different trial duration is unlikely to limit the validity of the mixed treatment comparison as the steady state is reached much earlier for both compounds, and neither of these has shown tolerance or tachyphylaxis.
In summary, we value Donohue's comments on our paper, and agree with many of them. We do, however, believe that these limitations of the research were acknowledged in the primary publication. Nevertheless, in the LAMA-free and "LAMA add-on" analyses, there is sufficient degree of overlap in terms of concomitant medication use and disease severity to allow for comparison of these two new important LABA treatments. We hope, in the absence of head-to-head data, that our paper gives a feel for how these treatments may be compared, at least for trough $\mathrm{FEV}_{1}$, and we also believe that our paper helps to highlight the problems with such analyses in this disease area given the heterogeneity in trial designs.

\section{Disclosure}

The authors report no conflicts of interest in this correspondence.

\section{References}

1. Roskell NS, Anzueto A, Hamilton A, Disse B, Becker K. Once-daily long-acting beta-agonists for chronic obstructive pulmonary disease: an indirect comparison of olodaterol and indacaterol. Int J Chron Obstruct Pulmon Dis. 2014;9:813-824.

2. Korn S, Kerwin E, Atis S, et al. Indacaterol once-daily provides superior efficacy to salmeterol twice-daily in COPD: a 12-week study. Respir Med. 2011;105(5):719-726.

3. Buhl R, Dunn LJ, Disdier C, et al. Blinded 12-week comparison of oncedaily indacaterol and tiotropium in COPD. Eur Respir J. 2011;38(4): 797-803.

4. Kinoshita M, Lee SH, Hang LW, et al. Efficacy and safety of indacaterol 150 and $300 \mu \mathrm{g}$ in chronic obstructive pulmonary disease patients from six Asian areas including Japan: a 12-week, placebo-controlled study. Respirology. 2012;17(2):379-389.

\section{Publish your work in this journal}

The International Journal of COPD is an international, peer-reviewed journal of therapeutics and pharmacology focusing on concise rapid reporting of clinical studies and reviews in COPD. Special focus is given to the pathophysiological processes underlying the disease, intervention programs, patient focused education, and self management protocols.

\section{Dovepress}

This journal is indexed on PubMed Central, MedLine and CAS. The manuscript management system is completely online and includes a very quick and fair peer-review system, which is all easy to use. Visit http://www.dovepress.com/testimonials.php to read real quotes from published authors. 